Pak. J. Agri., Agril. Engg., Vet. Sci., 2020, 36 (2): 97-100

ISSN: 1023-1072 (Print), ISSN: 2663-7863 (Online)

https://doi.org/10.47432/2020.36.2.2

\title{
STABILITY ANALYSIS FOR SEED COTTON YIELD OF NEWLY DEVELOPED UPLAND COTTON GENOTYPES
}

\author{
S. Abro ${ }^{1 *}$, M. T. Rajput ${ }^{2}$, M. A. Sial ${ }^{1}$, Z. A. Deho ${ }^{1}$ and M. Rizwan ${ }^{1}$ \\ ${ }^{1}$ Nuclear Institute of Agriculture (NIA) Tandojam, Pakistan \\ ${ }^{2}$ Preston University Karachi, Pakistan
}

\begin{abstract}
Sixteen newly evolved upland cotton strains developed through conventional and mutation breeding techniques along with two commercial check varieties viz., CIM-496 and CRIS-134 were evaluated two years at five locations in province of Sindh, Pakistan. Information was recorded on seed cotton yield from all location and analyzed statistically. To assess the stability for yield between genotypes and stomata studies was performed. The results from the combine analysis of variance depicted that the mean square for seed-cotton yield for genotypes and genotype $x$ environment interaction $(G \times E)$ were highly significant. Genotypes NIA-M-30 showed the maximum seed cotton yield (3.509 ton/ha) with low regression coefficient $(b=0.893)$ and deviation from regression coefficient $\left(S^{2} d=0.015\right)$. Other four genotypes viz., NIA-80, NIA-83, NIA-Bt-2 and NIA-Perkh also produced higher yield (3.36, 3.32, 3.31 and 3.25 ton/ha respectively) with regression coefficient $(b=0.972,0.918,0.99$ and 0.916 respectively) and deviation from regression coefficient $\left(S^{2} d=0.025,0.003,0.00\right.$ and 0.024 respectively), indicated wide adaptability to the range of environments. While the cotton genotypes NIA-HM-327, NIA-84 and NIA-HM48 showed high regression coefficient $(b=1.204,1.331$ and 1.291 respectively), which suggest their specific adaptation to favourable environments.
\end{abstract}

Keywords: cotton (Gossypium hirsutum L.), genotypes, regression coefficient, stability analysis and yield

\section{INTRODUCTION}

Cotton crop is grown as cash crop globally and that is a natural white fiber (Constable 2015). Improvement in seed cotton yield is one of the focal endeavors of cotton (Gossypium hirsutum L.) breeding. Cotton is grown in tropical and subtropical agro-ecological zones. Therefore, it is important to assess the performance of promising genotypes for adaptation and yield stability across environments. Environmental factors like temperature, humidity, day length, time of sowing characteristics and types of soil and also soil fertility varies over time and places in a particular region. Environmental factors strongly influence the crop growth stages (Sial et al., 2000), therefore, genotypes behave differently in their response to the environment (Bull et al., 1992). Many researchers believe that the selection criterion for genotype should not be solely dependent on average high yield but its superiority its performance is confirmed under different environmental conditions unless its

"Corresponding author' saifsabro@gmail.com performance is confirmed under different environmental conditions (Naveed et al., 2006; Golmirzaie et al., 1990; Qari et al., 1990; Kinyua 1992; Liu et al., 1992).

Sustainable production requires development of stable cultivars that can produce optimum yields in different agro climatic conditions. Therefore, identification of stable and more adaptable strains is an important aspect of cultivar development. In cotton, stability studies are necessary prior to the release of new varieties. Several methods for assessing stability of genotypes in diverse environments are available (Finlay and Wilkinson, 1963; Eberhart and Russell, 1966; Brown et al., 1983). Eberhart and Russel (1966) proposed a model of stability analysis in which the genotype yields in the particular environment are obtained by subtracting the mean of all genotypes over environments from the average yield of all genotypes at each location. $S^{2} d$ as parameter stability and Regression coefficient (bi) is considered response parameter (Eberhart and Russell, 1966). Less response to environmental changes when "bi" is around 1.00 and therefore a 
greater adaptation. However, the genotype can be grown in the poor environment if bi is negative while $S^{2} d$ so important zero cancels the linear prediction. Therefore, performance of variety which may be provided (ie $S^{2} d=0$ ) is said to be stable. Magnitude of genotype $x$ environment interactions is a desirable attribute depends on the stability in the performance of a genotype in different environments (Ahmed et al., 1996). Therefore, keeping in view the above facts, this research was conducted to identify the most stable and adapted genotypes in different environments, and the yield stability of newly developed cotton genotypes across the Sindh province.

\section{MATERIALS AND METHODS}

Sixteen newly evolved upland cotton (Gossypium hirsutum L.) strains developed through conventional and mutation breeding techniques along with two commercial check varieties viz., CIM-496 and CRIS-134 were evaluated. The multi-location trials of cotton genotypes were carried out during two cropping season 2014 and 2015. The experiments were conducted at 5 different locations in Sindh province of Pakistan having different agroclimatic conditions viz., Tandojam, Halla, Shaheed Benazirabad, Dadu and Khairpur. Each experiment was laid out in randomized complete block design (RCBD) with four replications. The plot size was $6.1 \mathrm{~m} \times 3 \mathrm{~m}$. Distance between plants within rows was $30 \mathrm{~cm}$. Agronomic and cultural practices i.e., weeding, hoeing, irrigation and fertilizer application were adopted as and when required. The data collected were analyzed for seed-cotton yield and subjected to analysis of variance, following Steel et al. (1997) using STATISTIX® VERSION 8.1. Stability analysis of the genotypes was done for seed-cotton yield data from replicated trials at multi-environments. Analysis comprised of combined analysis of variance for any place/environment (Pooled ANOVA). Stability parameters were calculated following Eberhart and Russell Model (1966).

\section{RESULTS AND DISCUSSION}

As a source of breeding material an ideal genotype must have high yield and nearest unit regression. Eberhart and Russel, (1966) proposed a model of stability analysis in which the genotype yields in the particular environment are obtained by subtracting the mean of all genotypes over environments from the average yield of all genotypes at each location. The value of regression co-efficient (bi) expresses the adaptation of genotype to specific environment where performance of genotype is regressed on environmental resources. Therefore, to assess stability of genotype, both $S^{2} d$ and regression were used. The combined ANOVA of seedcotton yield of 18 genotypes exhibits significant genetic variation (Table 1). These outcomes are dependable with earlier conclusion of Naveed et al. (2006); Sial et al. (2000) and Riaz et al. (2013).

Table 1. Combined analysis of variance for seedcotton yield of cotton genotypes tested over different environments 2014 and 2015

\begin{tabular}{|l|l|l|l|l|}
\hline Source & DF & SS & MS & F \\
\hline Replicates & 3 & 0.0806 & 0.02687 & \\
\hline Locations & 4 & 17.6815 & $4.42037^{* *}$ & 288.24 \\
\hline varieties & 17 & 10.0147 & $0.5891^{* *}$ & 38.41 \\
\hline $\begin{array}{l}\text { Locations } \\
{ }^{*} \text { varieties }\end{array}$ & 68 & 4.0738 & $0.05991^{\star *}$ & 3.91 \\
\hline Error & 267 & 4.0946 & 0.01534 & \\
\hline
\end{tabular}

The average performance of genotypes at various sites is presented in Table 2. Mean yield of genotypes was significantly higher as compared check varieties. Genotypes NIA-M30 (3.5 ton ha $\left.{ }^{-1}\right)$, NIA-80 (3.3 ton ha $\left.{ }^{-1}\right)$, NIA-83 (3.3 ton ha ${ }^{-1}$ ) and NIA-HM2-1 (3.3 ton ha ${ }^{-1}$ ) produced the highest mean seed-cotton yield as compared to check varieties CIM-496 (3.0 ton $\left.\mathrm{ha}^{-1}\right)$ and CRIS-134 (3.0 ton ha $\left.{ }^{-1}\right)$, respectively. The results obtained through this study will be helpful in achieving breeder's goals while selecting stable genotypes with acceptable yield over a range of environments.

The studies on stability parameters calculated for yield of seed-cotton genotypes in both the years. The wide variation in slope (b) of cotton genotypes was observed which indicated the strong genotype $x$ environment interaction in this region. Regression coefficient (b) value of genotypes ranged from 0.644 in genotype NIA-HM2-1 to 1.33 in NIA-84. Mutant line NIA-M-30 showed the maximum seedcotton yield (3.509 ton/ha) with low regression coefficient $(b=0.893)$ and deviation from regression coefficient $\left(S^{2} d=0.015\right)$. Other four genotypes viz., NIA-80, NIA-83, NIA-Bt-2 and NIA-Perkh also produced higher yield (3.36, $3.32,3.31$ and 3.25 ton ha ${ }^{-1}$, respectively) with regression coefficient $(b=0.972,0.918,0.99$ and 0.916, respectively) and deviation from regression coefficient $\left(S^{2} d=0.025,0.003,0.00\right.$ and 0.024 , respectively). It indicated that these 
genotypes possess general stability and could be widely adapted to the range of environments. Therefore these could successfully be used for general cultivation, which suggested that these genotype as less reactive to the different environmental and as a result, more adaptive. While the cotton genotypes NIA-HM-327, NIA-84 and NIA-HM48 showed highest regression coefficient values $(b=1.204,1.331$ and 1.291 , respectively) which suggest their specific adaptation to favorable or high yielding environments (Table 2).

Table 2. Stability parameters for seed-cotton yield of cotton genotypes tested over different environments over two years 2014 and 2015

\begin{tabular}{|c|c|c|c|}
\hline Genotypes & $\begin{array}{l}\text { Over all } \\
\text { mean } \\
\text { seed- } \\
\text { cotton } \\
\text { yield (ton } \\
\text { ha }^{-1} \text { ) }\end{array}$ & \begin{tabular}{|l|} 
Variance \\
due to \\
Regression \\
coefficient \pm \\
S.E b \pm s.e(b)
\end{tabular} & \begin{tabular}{|l} 
Deviation \\
from \\
regression \\
coefficient \\
$\left(\mathbf{S}^{2} \mathrm{~d}\right)$
\end{tabular} \\
\hline NIA-80 & $3.37 \mathrm{~b}$ & $0.972 \pm 0.317$ & 0.025 \\
\hline NIA-81 & 3.19cdef & $1.071 \pm 0.076$ & 0.001 \\
\hline NIA-83 & $3.32 \mathrm{bc}$ & $0.918+0.107$ & 0.003 \\
\hline NIA-84 & $3.04 \mathrm{gh}$ & $1.331 \pm 0.082$ & 0.002 \\
\hline $\mathrm{NIA}-\mathrm{H} 32$ & $3.07 \mathrm{fgh}$ & $1.067 \pm 0.569$ & 0.08 \\
\hline NIA-M-30 & $3.51 \mathrm{a}$ & $0.893 \pm 0.245$ & 0.015 \\
\hline NIA-HM-327 & 3.16 defg & $1.204 \pm 0.390$ & 0.037 \\
\hline NIA-M31 & $3.00 \mathrm{~h}$ & $1.051 \pm 0.332$ & 0.027 \\
\hline NIA-Perkh & 3.26 bcde & $0.916 \pm 0.315$ & 0.024 \\
\hline NIA-HM-2-1 & $3.30 \mathrm{bc}$ & $0.644 \pm 0.368$ & 0.033 \\
\hline NIA-HM-48 & $3.07 \mathrm{fgh}$ & $1.291 \pm 0.195$ & 0.009 \\
\hline NIA-Bt-1 & 3.15 defg & $1.005 \pm 0.298$ & 0.022 \\
\hline NIA-Bt-2 & $3.32 \mathrm{bc}$ & $0.990 \pm 0.024$ & 0.00 \\
\hline NIA-Okra-24 & $2.78 \mathrm{i}$ & $0.989 \pm 0.177$ & 0.008 \\
\hline Sadori & $3.286 \mathrm{bcd}$ & $0.861 \pm 0.112$ & 0.003 \\
\hline $\begin{array}{l}\text { CRIS-342 } \\
\text { (Check) }\end{array}$ & 3.12efgh & $1.042 \pm 0.139$ & 0.005 \\
\hline $\begin{array}{l}\text { CIM-469 } \\
\text { Check) }\end{array}$ & $3.008 \mathrm{~h}$ & $0.936 \pm 0.15$ & 0.006 \\
\hline $\begin{array}{l}\text { CRIS-134 } \\
\text { Check) }\end{array}$ & 3.03gh & $0.82 \pm 0.094$ & 0.002 \\
\hline
\end{tabular}

According to Finlay and Wilkinson (1963), a variety performed well at all locations with higher mean yield and possesses 'b' value close to 1.0 considered is as wide adopted or stable over all environments. Variety has ' $b$ ' value less than 1.0 is considered as in particular adapted to harsh (unfavorable) atmosphere; while varieties with regression values higher than 1.0 possesses specific adaptation to positive or high yielding environments. Likewise, Eberhart and Russell (1966) used regression coefficient as a parameter of stability and retreated the mean yield of each one genotype on the mean of all genotypes for each environment. $S^{2} d$ as the factor of stability and regression coefficient (bi) is measured as factor of response. Therefore, performance of variety which may be provided $S^{2} d=0$ is said to be stable. A genotype can be guess to be stable when their performance is $S^{2} d=0$. Assuming $S^{2} d=0$, a high value of bi and mean more change for a unit change in (bi). In other words, variety is more sensitive (Sarwar et al., 2003). This variety can, therefore, be recommended only for highly favorable environments, say under high fertility. A relatively low value of bi, say about 1 , mean less sensitive to changes in the environment and therefore more adaptable. These results are in accordance with the findings of some previous studies (Killi and Harem, 2006; Khan et al., 2007; Riaz et al., 2013) which reported the stability and $G \times E$ interaction in genotypes of cotton and the effect of different environments on SCY to understand their adaptation to different environments.

\section{CONCLUSION}

In the end, this research illustrated the occurrence and kind of relations between the $G$ $x E$ of 18 cotton genotypes and their seed-cotton yield. Among the genotypes, NIA-M-30 NIA-80, NIA-83, NIA-Bt-2 and NIA-Perkh showed the maximum seed-cotton yield with low regression coefficient and deviation from regression coefficient indicated wide adaptability to the range of environments. While the cotton genotypes NIA-HM-327, NIA-84 and NIA-HM48 showed highest regression coefficient values, which suggest their specific adaptation to favourable environments.

\section{AUTHOR'S CONTRIBUTION}

S. Abro: Conceived the idea, recorded data in field, prepared draft and finalized the manuscript M. T. Rajput: Helped in formulating the study and supervised the work

M. A. Sial: Co-supervised the work and helped in field experiment planning

Z. A. Deho: Helped in execution of field experiment

M. Rizwan: Helped in data recording, analysis, writing and proof reading of the manuscript

\section{REFERENCES}

Ahmad, J., M. H. Chaudhry, S. Salah-ud-Din and M. A. Ali. 1996. Stability for grain yield in wheat. Pakistan Journal of Botany, 28: 61-66.

Brown, K. D., M. E. Sorells and W. R. Coffinan. 1983. A method for classification and evaluation of testing environments. Crop Sciences, 23 (5): 889-893. 
Bull, J. K., M. Cooper, I. H. Delacy, K. E. Bassford and D. R. Woodruff. 1992. Utility of repeated checks for hierarchical classification of data from plant breeding trials. Field Crop Research, 30 (1-2): 79-95.

Constable, G. A. and M. P. Bange. 2015. The yield potential of cotton (Gossypium hirsutum L.). Field Crops Research, 182: 98-106

Eberhart, S. A. and W. A. Russell. 1966. Stability parameters for comparing varieties. Crop Science, 6 (1): 36-40.

Finlay, K. W. and G. N. Wilkinson. 1963. The analysis of adaptation in a plant breeding programme. Australian Journal of Agricultural Research, 14 (6): 742-754.

Golmirzaie, A. M., J. W. Schmidt and A. F. Dreier. 1990. Components of variance and stability parameters in studies of cultivars $x$ environment interaction in winter wheat (Triticum aestivum L.). Cereal Research Communications, 18: 249-256.

Khan, N. G., M. Naveed, N. U. Islam and M. S. lqbal. 2007. Assessment of new upland cotton genotypes (Gossypium hirsutum L.) for yield stability and adaptability. Asian Journal of Plant Sciences, 6: 1012-1015.

Killi, F. and E. Harem. 2006. Genotype $\times$ environment interaction and stability analysis of cotton yield in Aegean region of Turkey. Journal of Environmental Biology, 37 (2): 427-430.

Kinyua, M. G. 1992. Genotype × environment effects on bread wheat grown over multiple locations and years in Kenya. In: $7^{\text {th }}$ Regional Wheat Workshop for Eastern, Central and Southern Africa Nakuru Kenya, pp.103-107.
Liu, L. X., T. C. Haung, G. T. L. Liu and S. Z. Zhang. 1992. Stability analysis of yield and quality characters of hybrid and pure line winter wheat cultivars. Acta Agronomica Sinica, 18: 38-49.

Naveed M., N. Mukhtar, J. Farooq, M. llyas and Noor-ul-Islam. 2006. Evaluation of some new strains of Gossypium hirsutum L. for yield stability across environments. Journal of Agriculture and Social Science (E), 7: 8421185-62.

Qari, M. S., N. I. Khan and M. A. Bajwa. 1990. Comparison of wheat cultivars for stability in yield performance. Pakistan Journal of Agriculture Research, 11 (2): 73-77.

Riaz, M., M. Naveed, J. Farooq, A. Farooq, A. Mahmood, C. M. Rafiq, M. Nadeem and A. Sadiq. 2013. AMMI analysis for stability, adaptability and GE interaction studies in cotton (Gossypium hirsutum L.). Journal of Animal and Plant Science, 23 (3): 865-871.

Sarwar, G., M. S. Sadiq, M. Saleem and G. Abbas. 2003. Genotype x environment interaction in newly developed lentil germplasm under cotton based cropping system. In: Sustainable Utilization of Plant Genetic Resources for Agricultural Production, pp. 219-226.

Sial, M. A., M. A. Arain and M. Ahmad. 2000. Genotype $\mathrm{x}$ environment interaction on bread wheat grown over multiple sites and years in Pakistan. Pakistan Journal of Botany, 32 (1): 85-92.

Steel, R. G. D., J. H. Torrie and D. A. Dickey. 1997. Principles and procedures of statistics: A biometrical approach. New York: McGraw Hill Book Co. Inc, 400-428.

(Received: November 06, 2020; Accepted: December 22, 2020) 